\title{
MEGDEL syndrome
}

INSERM

\section{Source}

INSERM. (1999). Orphanet: an online rare disease and orphan drug data base. MEGDEL syndrome. ORPHA:352328

MEGDEL syndrome is a rare, genetic, neurometabolic disorder characterized by neonatal hypoglycemia, features of sepsis that are not linked to infection, development of feeding problems, failure to thrive, transient liver dysfunction, and truncal hypotonia followed by dystonia and spasticity which results in psychomotor development arrest and/or regression. Progressive sensorineural deafness, intellectual disability and absent speech are also associated. Laboratory tests demonstrate 3-methylg lutaconic aciduria and temporary elevated serum lactate and transaminases. 